\title{
A RELEVANCE-THEORETIC ANALYSIS OF YEAH AS A DISCOURSE MARKER
}

\author{
Dam Ha Thuy* \\ VNU University of Languages and International Studies \\ Pham Van Dong, Cau Giay, Hanoi, Vietnam \\ Received 18 February 2019 \\ Revised 25 April 2019; Accepted 31 May 2019
}

\begin{abstract}
The paper attempts to explain English native speakers' use of the discourse marker yeah from a relevance-theoretic perspective (Sperber \& Wilson, 1995). As a discourse marker, yeah normally functions as a continuer, an agreement marker, a turn-taking marker, or a disfluency marker. However, according to Relevance Theory, yeah can also be considered a procedural expression, and therefore, is expected to help yield necessary constraints on the contexts, which facilitates understanding in human communication by encoding one of the three contextual effects (contextual implication, strengthening, or contradiction) or reorienting the audience to certain assumptions which lead to the intended interpretation. Analyses of examples taken from conversations with a native speaker of English suggest that each use of yeah as a discourse marker is able to put a certain type of constraints on the relevance of the accompanying utterance. These initial analyses serve as a foundation for further research to confirm its multi-functionality as a procedural expression when examined within the framework of Relevance Theory.
\end{abstract}

Keywords: Relevance Theory, yeah, discourse marker, contextual effects, constraints on relevance

\section{Introduction}

\subsection{Rationale}

Relevance theory (RT) developed by Wilson and Sperber in 1986 is an inferential approach to the study of human communication. Its purpose is to elaborate on a Gricean claim that human communication is characterized by "the expression and recognition of intentions" (Wilson \& Sperber, 2004, p. 607). RT's major claim is that cognitive processes in human beings are supposed to obtain as great "cognitive effect" as possible while making as little "processing effort" as possible (Sperber \& Wilson, 1995, p. vii).

\footnotetext{
Tel.: 84-913259155
}

Email: damhathuy@yahoo.com.
RT has been adopted by many linguists such as Blakemore (1992), Jucker (1993), Carston (1993) and Schourup (2011) as their framework to account for a variety of phenomena in human communication. One of their common interests is the application of RT in explaining the use of discourse markers to maximize the relevance in verbal communication. The term "discourse marker" is not a new concept in linguistics. However, there has been much dispute over not only the functions but also the categorization of these linguistic elements (Jucker, 1993), and RT also has its own approach to this issue.

\subsection{Purposes}

Within the framework of RT, a number of discourse markers have been analyzed, for example, well by Jucker (1993), now by 
Schourup (2011), Singaporean lah and meh by Vivien (2006) and discourse connectives by Blakemore (2002). Even in the field of language translation, the meaning of discourse markers (well) is also based on the maximum contextualization of the token (Ngô Hữu Hoàng, 2010). RT has been claimed to provide a rational explanation for the use of those markers in all of the verbal communication settings under investigation. Therefore, the application of RT in analyzing other discourse markers seems to be a promising approach.

Besides, although there has been a great deal of research on discourse markers which uses RT as their guidance, it seems that none of them has touched the issue of token yeah. From the available literature, yeah has mostly been explained within Conversation Analysis (Drummond \& Hopper, 1993; Wong, 2000). This gap has triggered my motivation to produce a research paper to explain the use of yeah within the framework of RT.

\subsection{Scope}

This is a small-scale study which aims to test the applicability of RT in explaining the uses of yeah. Therefore, data collected from a 10-minute interview with one native English speaker has been used for analysis though there was another non-native speaker participant. The length of the interview was to ensure the production of a sufficient number of the token $y e a h \mathrm{~s}$ for analysis. The reason for the choice of the native speaker's data for analysis is that native speakers' choice of a linguistic element is appropriate for the function it is aimed to realize while non-native speakers are likely to develop fossilization in discourse marker use (Trillo, 2006).

\section{Literature review}

\section{Yeah as a discourse marker}

The token yeah has been the topic of interest to many linguists (Drummond \& Hopper, 1993; Wong, 2000; Fuller, 2003). In one of the papers (Trillo, 2006), yeah is categorized in the group of acategorical discourse markers. According to Trillo, discourse markers in general have been discourse grammaticalized to include a pragmatic aspect in order to serve "interactional purposes" and become part of a system which "constrains the relevance of the proposition it introduces" (p. 641). This view has some similarity with that proposed by RT, strengthening the possibility that yeah can be analyzed within the framework of RT. There are possibly four major uses of yeah that have been documented in previous studies, each of which is briefly described in the following part.

- Turn-initial yeah as a continuer

A story-recipient uses yeah as a signal to the speaker that the hearer is still paying attention to the flow of the story and does not have the intention of assuming speakership. The "minimal response" yeah acts as an encouragement for the speaker to continue his extended speaking turn (Fuller, 2003, p. 29). Therefore, it is called "a continuer" (Wong, 2000, p. 41).

- Turn-initial yeah as an agreement marker

Although researchers have disagreement about this use of yeah as a discourse marker (Drummond \& Hopper, 1993; Fuller, 2003), it may still be worth investigating within RT. Yeah in these cases serves as an affirmative answer to a Yes-No question, being a secondpair part to an adjacency pair (Drummond \& Hopper, 1993; Wong, 2000). It is often freestanding and is not included in any other units of utterance; however, it can occur 
"approximate to a current telling" and may be used by either the speaker or the hearer of the story. However, sometimes confusion occurs between this use and the continuer use (Drummond \& Hopper, 1993).

- Turn-initial yeah as a turn-taking marker

The story recipient uses yeah to signal his intention to begin his turn in the conversation so that the current speaker leaves the speakership for him to take over. The recipient starts his turn with yeah and continues with further talk and gains the speakership instead of remaining a "passive hearer" (Wong, 2000, p. 44). The shift in speakership is often accompanied by a "shift in the topic" as introduced by the new speaker after the use of yeah (Wong, 2000; Fuller, 2003, p. 37).

- Turn-medial yeah as a pause/disfluency/ repair marker

Wong (2000, p. 61) states that this use of yeah in native speakers is rare and seems to "mark failure of the search" for an appropriate linguistic item to use in a certain circumstance. However, it appears that there is something that RT has available to explain for this kind of disfluency. Therefore, this use of yeah is still included herein.

It should be noted that the examples in the discussion of yeah within RT framework may not strictly distinguish yeahs in the above categorization as yeah can sometimes serve more than one function in a particular circumstance (Drummond \& Hooper, 1993, Fuller, 2003).

\section{Principles of relevance}

As aforementioned, RT is to account for human communication by explaining cognitive processes. RT considers utterances as inputs to human inferential processes through which the cognitive environment of the hearer is modified (Sperber \& Wilson, 1995). In order to interpret an utterance, a hearer first has to decode the message which is represented by "linguistically encoded logical form" and then contextualizes it and builds hypothesis about the speaker's intention (Wilson \& Sperber, 1993, p. 1).

There are two central principles on which RT is founded - the Cognitive Principle of Relevance and the Communicative Principle of Relevance. The first one states that "human cognition tends to be geared to the maximization of relevance" (Wilson \& Sperber, 2004, p. 610). An input is said to be relevant to the hearer only when it interacts with the available background, and he has to "yield conclusions that matter to him" (p. 608). Such conclusions, then, are said to have a "positive cognitive effect" (referred to as contextual effect hereafter). In order for a contextual effect to be achieved, the context for an utterance interpretation must be gradually and constantly changing, contributing to the greater contextual effects achieved in the communication (Sperber \& Wilson, 1995). Contextual effect is thus said to be a necessary condition for relevance. The degree of relevance, however, is also decided by the effort which people have to make in processing information (Wilson \& Sperber, 2004).

The second principle involves communication, claiming that "every ostensive stimulus conveys a presumption of its own optimal relevance" (Wilson \& Sperber, 2004, p. 612). It means that the set of assumptions that the communicator intends to make manifest to his audience must be relevant enough "to be worth the audience's processing effort" and "the most relevant one compatible with communicator's abilities and preferences" (p. 612). The assumptions are 
said to be manifest to a person if and only if he is capable of "representing it mentally and accepting its representation as true or probably true" (Sperber \& Wilson, 1995, p. 39). In fact, this principle deals with the effect achieved and effort required during the inferential process. A stimulus is worth paying attention to only when it appears to be more relevant than any other stimulus available to the audience, costing the audience the least effort in his attempt to process it. With regard to the communicator, he is expected to try to make as clear as possible the evidence not only for the cognitive effect he wants to achieve in his audience but for "further cognitive effects" which enable him to accomplish his goals (p. 257).

As can be seen, RT revolves around the attempt of a communicator to guarantee the greatest contextual effect achieved and the least processing effort made in communication in a given context.

\section{Contextual effects}

Context in RT is defined as "a subset of the individual's old assumptions" which is combined with new assumptions to produce contextual effects in the processing of such new assumptions (Sperber \& Wilson, 1995, p. 132). Contextual effect is the result of the contextualization of the new information in the set of old information available to the hearer.

Contextual effect is achieved when a context is modified and improved. However, not all modifications will result in an effect. According to Sperber and Wilson (1995), in order for a contextual effect to be achieved, the new and old assumptions (information) must be related to each other in some way, not just a duplication or unrelated addition. These relations form three types of contextual effects as presented below.
- Contextual implication

Contextual implication is seen as an addition of the newly presented information to the old information drawn from an existing representation of the world in which both types of information are regarded as premises in a synthetic implication (Sperber \& Wilson, 1995). In RT, assumptions derived from encyclopedic memory are seen as old information whereas those emerging from perception or linguistic decoding are new information which then will become old information for the processing to yield further contextual implication. Sperber and Wilson call contextual implication a synthesis of old and new information, suggesting that the interpretation of an utterance (new information) is affected by the particular context (set of old information) in which it is processed.

\section{- Strengthening}

Strengthening is a kind of contextual effect which results from the fact that the newly presented information provides further evidence for the old information, helping to consolidate the old assumptions. There are two types of strengthening - the dependent and independent strengthening.

In dependent strengthening, the strength of the conclusion depends on both the added information and the available context (Sperber \& Wilson, 1995). If both premises (old and new assumptions) are certain, then the conclusion is certain. If one of the premises is certain and the other one is not, the strength of the conclusion is that of the weaker premise. If neither of the premises is certain, the conclusion will inherit the strength which is lower than that of the weaker premise.

In independent strengthening, a conclusion is "independently implied by two different 
sets of premises" (Sperber \& Wilson, 1995 , p. 112). It is said that the strength of an assumption already existing in human cognition will be affected by the occurrence of the same assumption which is built on a different set of premises. In this case, the strength of the conclusion is greater than the strength of each individual set of premises.

- Contradiction

This kind of contextual effect results from "a contradiction between new and old information", which leads to the elimination of false assumptions (Sperber \& Wilson, 1995, p. 114). If two assumptions are found to contradict each other and their strengths can be compared, the weaker assumption will be eliminated. If it is impossible to compare them, human cognition will try to search for "further evidence for or against one of the contradictory assumptions" (p. 115). However, if the new assumption is eliminated, there will be no important contextual effect. Contextual effect is achieved only when the old assumption is displaced by the new assumption.

It can be seen that various interactions between the new information and the context in which it is processed can lead to different types of contextual effects which subsequently result in different types of relevance of an utterance in communication.

\section{Constraints on relevance}

It is said that linguistic expressions which have procedural meaning can guide the hearer in the process of utterance interpretation by making the context become as small as possible so that the processing effort is reduced. Such procedures are claimed to have certain "constraints on relevance" (Blakemore, 1987).
According to Wilson and Sperber (1993), there are two criteria to define a procedural expression. The first one is that "procedures cannot be brought to consciousness", which makes it very difficult to judge whether two procedural expressions are synonymous or not. The second one is that procedural expressions cannot combine with other expressions to form "semantically complex expressions" (Blakemore, 2006, p. 564). From this point of view, it is likely that yeah can be considered a procedural expression.

Procedural encoding has been applied to explain the use of a variety of discourse markers in constraining the context for utterance interpretation (Blakemore, 1987). They are analyzed as encoding one of the three types of contextual effects. The three following examples illustrate how discourse markers can constrain the selection of context for utterance interpretation.

Example 1: (a) Peter has passed the exam. (b) After all, he is a good student.

By using after all, the speaker has suggested the inferential route that the hearer has to take in order to interpret the above utterance. In this route, the proposition expressed in (b) is a premise for the deduction of the proposition expressed in (a). The speaker, therefore, is indicating that (b) is relevant as it has strengthened the assumption which has already existed in (a).

Example 2: (a) I know where the restaurant is. (b) So we do not need the GPS.

Unlike the above example, the use of so in example 2 suggests that the inferential route the hearer is expected to follow is considering (b) a conclusion derived in an inference in which the proposition expressed in (a) plays the role of a premise. The speaker is indicating that (b) is relevant as it has yielded 
a contextual implication by combining with the existing assumption in (a).

\section{Example 3: (a) I have a lot of homework} to do, (b) but I'm still going to the concert.

In this example, the relevance of (b) is guaranteed in the fact that it contradicts and eliminates an assumption presumed to have been made manifest by (a) which may be "I need to finish the homework before doing anything else". The inferential route in the third example leads the hearer to the elimination of the existing assumption made in (a); therefore, it has produced the contradiction type of contextual effect.

However, there are also some cases in which the meaning of a discourse marker does not lead to the activation of contextual effects but encodes a signal that the hearer can "go ahead with the inferential processes involved in the derivation of cognitive effects" (Blakemore, 2002, p. 147). For example, the inclusion of well in an utterance indicates the speaker's guarantee of the cognitive effects that will be achieved if his utterance is processed. Blakemore calls this "reorienting the hearer to a context of assumptions which will yield the intended interpretation" ( $p$. 144). This reorienting process may result from the speaker's belief that the hearer may not recognize the relevance of a contextual assumption which he should have recognized. For example:

\section{A: Today is so cold and it's June. \\ B: Well, it's the winter now in Australia.}

The use of well in B's utterance is to encourage $A$ to recognize the assumption about the time of winter in Australia which B believes that $\mathrm{A}$ does not recognize at all. In this case, A's utterance is treated as evidence that A believes that June is the summer time everywhere in the world.
In other cases, reorienting happens when the speaker expects that the hearer should know the constraints that the speaker's preferences and capabilities have imposed on the level of relevance attempted. For example:

A: Did you finish your homework?

B: Well, not yet.

The use of well in B's answer may not be considered to lead to the most relevant assumptions from the hearer's point of view; however, it still leads to the derivation of further assumptions which are relevant if the speaker's preference is taken into account. The relevance is constrained by the speaker's desire that he is not such a lazy student and there would be some reasons for his not completing the homework.

As can be seen, procedural expressions play a significant role in constraining the relevance of the utterance containing them. These expressions can help either yield the intended cognitive effects or reorient the hearer to a context which will yield the intended interpretation (Blakemore, 2002). The analyses of the uses of yeah in the coming part also follow this path.

\section{Methodology}

\subsection{Framework}

As stated above, this paper aims to explain different uses of yeah within the framework of Relevance Theory. Although RT includes a great many concepts related to the cognitive processing of human communication, this paper only employs the notion of contextual effects and constraints on relevance to explain how yeah can contribute to the relevance of the utterance in which it appears or to which it attaches to. It is a popular approach to analyze procedural expressions in general and 
discourse markers in particular throughout the development of RT (Jucker, 1993; Blakemore, 2002; Vivien, 2006).

\subsection{Research question}

Using RT as a general framework to analyze different functions of yeah, the objective of this paper is to seek the answer to the following research question: "How can the four uses of Yeah by an English native speaker in a specific interview be explained with the notion of constraints on relevance?"

\subsection{Data collection procedure}

The 10-minute interview was conducted after a brief description about the study was presented to the participant (an Australian English native speaker) and he agreed to participate and have his data used for research purpose by signing the consent form. I (the researcher) also asked for his permission to audio-record our interview for later analysis. The topic of the interview (hobbies and pastimes) was also revealed beforehand so that the participant could orientate himself and have an overall expectation of what he would talk about in the conversation.

\subsection{Data analysis procedure}

The interview was transcribed for further analysis. However, because this paper does not use Conversation Analysis as its framework, the transcription is not a detailed one. It only includes the utterances and some major signals for intonation and pauses if necessary.

In the forthcoming Discussion, four examples representing four uses of yeah are analyzed in order to illustrate the above purpose. These examples are taken from the 10-minute interview between the researcher and the English native speaker described above. Also as aforementioned, the choice of data from a native speaker is justified by the fact that the native speaker's use of discourse markers represents a kind of "linguistic competence" which guarantees the naturalness and appropriateness of the uses of yeah for more accurate analysis (Trillo, 2006, p. 641).

Yeah has been used several times in the interview with different purposes. However, it should be noted that these uses sometimes overlap each other. Therefore, one example can be used as an illustration for one use even when it can be used for analysis for another use as well. The examples are presented in the form of conversations in which I am the one to open the dialogue and/or pose a question and the interviewee is the one to extend the dialogue and/or give the answer.

\section{Results and discussion}

The relevance-theoretic analysis of yeah is presented according to its uses, each of which is illustrated with one example.

- Yeah as a continuer

In the following context, the interviewer (A) wanted to ask about the participant's (B) pastime which is boating. I drew his attention to the topic of his "boat" by stating an affirmative with a raising tone.

A: So I notice that you have a boat here?

B: $\underline{\text { Yeah? }}$

A: So what do you do with it?

B acknowledges A's prelude by saying yeah also with a raising tone. The use of yeah in this context can be considered an encouragement that A can continue with her question.

$\mathrm{B}$ believes that in order to be relevant, A has tried to make manifest some assumptions 
she has already had about "the boat". These assumptions which partly build up the context in which subsequent utterances are processed might be:

[1] I see a boat in your backyard.

[2] If the boat is in your house, it must be yours.

B's yeah indicates to A an inferential route in which the assumptions expressed in B's answer has strengthened the existing assumptions made manifest by A. B's yeah has constrained the context for A's inference. The assumptions that $\mathrm{B}$ has attempted to make manifest to strengthen A's already existing assumptions could be:

[3] It is true that this boat is mine.

[4] I am willing to talk about it if you want.

As the contextual effect (strengthening) has been achieved and the two set of assumptions (premises) are certain, the conclusion that A may come up with is also certain. That conclusion can be "now I can ask you something about your boat". As a result, the conclusion has been made manifest in A's utterance that is "so what do you do with it?"

- Yeah as an agreement marker

In this conversation, $\mathrm{A}$ and $\mathrm{B}$ are talking about the Australian football to which "it" refers.

A: Do you like it?

B: Yeah...yeah, my team I support is Collingwood.

$\mathrm{B}$ has given an affirmative answer to A's Yes-No question, confirming that he likes watching Australian football. After that, he continues to add some more information about his interest.
$\mathrm{B}$ is not only answering A's question but trying to make manifest his attempt to be optimally relevant by strengthening the assumptions he believes that $\mathrm{A}$ has made manifest to him which may include:

[1] Australia has a particular kind of football.

[2] Australian people like this kind of football very much.

[3] You are Australian.

[4] You may also like it very much.

Yeah in B's answer has guided A to follow an inferential route in which the context $A$ has set up for the processing of B's utterance has been strengthened. The assumption B believes that he has made manifest to A by saying yeah can be:

[5] I like Australian football.

[6] I will give you more information to prove that it is my hobby.

With his belief that these above assumptions have been made manifest to A, B continues his turn with "my team I support is Collingwood". The contextual effect, therefore, has been made greater by this utterance. The new set of assumptions contained in this utterance are newly presented information and closely related to the old set of assumptions above. The interaction between these two set of premises has yielded a contextual implication.

- Yeah as a turn-taking marker

$\mathrm{A}$ and $\mathrm{B}$ are talking about soccer and $\mathrm{A}$ is sharing that Leo - her husband (who B also knows) likes it very much. B acknowledges A's information and shifts the topic back to the Australian football.

A: Leo likes soccer a lot. He's a crazy fan of soccer. 
B: Yeah...yeah... soccer...yeah...it's more international but football is Australian. It is the most popular sport here.

The double yeah at the beginning of B's turn suggests its role of strengthening the set of assumptions that B believes $\mathrm{A}$ has attempted to make manifest:

[1] Leo is not an Australian.

[2] Many non-Australian are crazy about soccer.

[3] Leo crazily likes soccer.

B can also employ his encyclopedic memory about "soccer" which may store this information "soccer is the most popular sport in the world". Combining these assumptions together, he has come to the conclusion which begins with yeah. His use of yeah is believed to provide the constraint on the context that A may use to interpret B's further utterances. In this case, it has a strengthening contextual effect.

It seems that this third use looks no different from the previous ones. However, it can be noticed that in this example, yeah appeared three times in B's utterance. The repetition of yeah seems to be an attention getter which B uses to encourage A to recognize some contextual assumptions which $\mathrm{B}$ believes to be relevant but is afraid that they have not been recognized by $\mathrm{A}$ as relevant. Those assumptions may be:

[4] You may want to interrupt me to continue talking about soccer.

[5] Unlike you, I want to talk more about football instead.

In fact, after believing that these above assumptions have been communicated to A, B continues his turn by using but to yield a contradiction and talks more about football.
Although I consider B's utterance as a topicshifter, it does not quite resemble that mentioned in Wong (2000) and Fuller (2003). Perhaps B, in order to be polite, is attempting to be as relevant as possible by not suddenly changing the focus of the conversation he is engaging in.

- Yeah as a pause/disfluency/repair marker

There are several yeahs in the following excerpt. However, the focus of the analysis is the last one in B's utterance which seems to prove B's disfluency in search of an adjective to describe his sons who were talked about previously in their conversation.

A: So, do you enjoy it...ah with your sons or...?

\section{B: Like basketball?}

A: Yeah, basket ball or boating or...

B: Yeah yeah yeah, but now, you know, they're getting a little bit...yeah...they're getting a little bit older now, so they prefer to go with their friends.

The first segment of B's utterance "but now, you know, they're getting a little bit..." suggests the contradiction between A's assumptions and those that $\mathrm{B}$ is trying to make manifest. B believes that A may have the following assumptions in asking her question of "So, do you enjoy it...ah with your sons or...?"

[1] You must play sport with someone else.

[2] You have two sons.

[3] It is likely that you often play sport with your sons.

But in B's answer has guided A to interpret that there is something opposite to A's assumptions. However, B seems to have difficulty in making his assumptions manifest to A, which may result in the loss of 
the contextual effect in particular and of the relevance of the utterance in general.

The use of yeah has been motivated by B's desire to communicate that he is temporarily incapable of making his assumptions manifest to A and would like A to maintain her attention. It encodes B's guarantee that there is still some contextual effect to come and B's utterance is still relevant if $\mathrm{A}$ is willing to wait until $\mathrm{B}$ has found the appropriate linguistic item to completely communicate the information he wants to make manifest to A. Yeah plays the role of reorienting A to B's intended contextual effect in the fact that the level of relevance attempted has been constrained by B's capabilities.

From the four examples above, it can be seen that all uses of yeah do constrain the relevance of the utterance it appears in or attaches to by either directly yielding the intended contextual effects or reorienting the hearer to the necessary contexts to yield such effects.

\section{Conclusion}

The paper has attempted to explain different uses of yeah as produced by an Australian English native speaker within the framework of Relevance Theory in general and with the notion of procedural expressions' constraints on relevance in particular.

It appears that this theoretical framework has fulfilled this purpose. While yeahs as a continuer and an agreement marker both directly yield a strengthening contextual effect, yeah as an agreement marker is also capable of indicating a further contextual implication. The other two uses, in contrast, indirectly yield the intended contextual effects by reorienting the hearer to the necessary contexts. Yeah as a turn-taking marker is a kind of attention getter to encourage the hearer to recognize a relevant assumption which the speaker thinks has not been recognized by the hearer. Meanwhile, yeah as a disfluency marker constrains the relevance by indicating the speaker's capabilities.

As this research is done with the data collected from a 10-minute interview with the participation of one single Australian English speaker, it would not attempt to generalize the results to a larger population of other native speakers of English. Also, researchers who share the same interest in this research area may extend the content of the interview to other topics of interest to decide if the four uses of yeah can be consistently explained in different contexts of communication. However, the fact that the four major uses of yeah have been successfully explained within the framework of Relevance Theory has laid a foundation for future research with a larger data set collected from different groups of English speakers. The fruition of this study has also suggested the possibility of conducting further studies to seek the answer to the question why yeah is able to constrain the relevance in a variety of ways, which is not often witnessed in other procedural expressions.

\section{References}

\section{Vietnamese}

Ngô Hữu Hoàng (2010). Hiểu và dịch tiểu từ well của tiếng Anh như một dấu hiệu diễn ngôn: Một nghiên cứu dịch thuật trên cơ sở ngũ̃ dụng học. Tạp chi Khoa hoc ĐHQGHN: Ngoại ngũ, 27(1), 17-21.

\section{English}

Blakemore, D. (1987). Semantic constraints on relevance. Great Britain: Basil Blackwell.

Blakemore, D. (1992). Understanding utterances. Oxford: Blackwell.

Blakemore, D. (2002). Relevance and linguistic meaning: The semantics and pragmatics of discourse markers. Cambridge: Cambridge University Press.

Blakemore, D. (2006). Meaning, procedural and conceptual. In Encyclopedia of Language \& 
Linguistics (2 ${ }^{\text {nd }}$ ed.). Boston: Elsevier.

Carston, R. (1993). Conjunction, explanation and relevance. Lingua, 90(1-2), 27-48.

Drummond, K., \& Hopper, R. (1993). Some uses of yeah. Research on Language \& Social Interaction, 26(2), 203-212.

Fuller, J. M. (2003). The influence of speaker roles on discourse marker use. Journal of Pragmatics, 35(1), 23-45.

Jucker, A. H. (1993). The discourse marker well: A relevance-theoretic account. Journal of Pragmatics, 19(5), 435-452.

Schourup, L. (2011). The discourse marker now: A relevance-theoretic approach. Journal of Pragmatics, 43(8), 2110-2129.

Sperber, D., \& Wilson, D. (1995). Relevance: Communication \& Cognition ( $2^{\text {nd }}$ ed.). Great Britain: Blackwell Publishers.

Trillo, J. R. (2006). Discourse markers. In Encyclopedia of Language \& Linguistics (2 $2^{\text {nd }}$ ed.). Boston: Elsevier.

Vivien, L. S. L. (2006). A relevance-theoretic approach to discourse particles in Singapore English. In K. Fischer (Ed.), Approaches to discourse particles (149-166). The Netherlands: Elsevier.

Wilson, D., \& Sperber, D. (1993). Linguistic form and relevance. Lingua, 90(1-2), 1-25.

Wilson, D., \& Sperber, D. (2004). Relevance theory. In L. R. Horns \& G. L. Ward (Eds.), The handbook of Pragmatics (607-632). Oxford: Blackwell Publishing.

Wong, J. (2000). The token "yeah" in nonnative speaker English conversation. Research on Language \& Social Interaction, 33(1), 39-67.

\title{
PHÂN TÍCH DẤU HIỆU DIỄN NGÔN YEAH DƯỚI GÓC Độ CỦA LÝ THUYẾT QUAN YẾU
}

\author{
Đàm Hà Thủy \\ Truò̀ng Đại học Ngoại ngũu, ĐHQGHN, \\ Phạm Văn Đồng, Cầu Giấy, Hà Nội, Việt Nam
}

Tóm tắt: Nghiên cứu này tập trung giải thích cách sử dụng dấu hiệu diễn ngôn yeah của người nói tiếng Anh bản ngữ dưới góc độ của lý thuyết quan yếu (Sperber \& Wilson, 1995). Yeah vốn được coi là một dấu hiệu diễn ngôn, đảm nhiệm một trong bốn chức năng là tạo ra dấu hiệu tiếp tục, dấu hiệu tán đồng, dấu hiệu kiểm soát lượt lời và dấu hiệu lắp. Tuy nhiên, nhìn từ thuyết quan yếu, yeah lại được coi là một biểu thị thủ tục, và vì vậy, yeah được kì vọng là sẽ giúp tạo ra câu thúc cần thiết lên ngữ cảnh, từ đó tạo điều kiện cho việc thông hiểu trong giao tiếp bằng cách mã hóa một trong ba hiệu ứng ngữ cảnh (hàm ẩn ngữ cảnh, tăng cường, hoặc mâu thuẫn) hoặc tái định hướng người nghe đến những giả thiết cụ thể nhằm dẫn đến diễn nghĩa đã định. Những phân tích các ví dụ về yeah của nghiệm viên chỉ ra rằng mối chức năng của yeah khi được sử dụng như một dấu hiệu diễn ngôn có khả năng tạo ra một câu thúc quan yếu nhất định lên phát ngôn đi theo nó. Những phân tích ban đầu này là cơ sở cho những nghiên cứu sâu hơn để khẳng định yeah là một biểu thị thủ tục đa chức năng khi được phân tích dưới góc nhìn của lý thuyết quan yếu.

Từ khóa: Thuyết quan yếu, yeah, dấu hiệu diễn ngôn, hiệu ứng ngữ cảnh, câu thúc quan yếu 